\title{
TURISTIČNA GEOGRAFIJA NA RAZPOTJU ${ }^{1}$
}

Socialna geografija trdi, da je sedem temeljnih dejavnikov sodobne družbe enakovrednih v svojem prostorskem izrazju. Prebivati, delati, izobraževati se, oskrbovati se, izražati se v političnem in kulturnem okolju, komunicirati in sproščati se (turistično in rekreacijsko delovati) sodijo v sodobni družbi k dejavnikom, ki so med seboj prepleteni in kompleksno delujejo v prostorski stvarnosti zatečenega trenutka oziroma obdobja. Mnogi avtorji oporekajo takemu stališču, vendar v socialno naravnani in demokratični državi slehernemu izmed naštetih dejavnikov odrejamo prostor, obenem pa naštete dejavnike registriramo pri vsakem »povzetku stanja« neke prostorske stvarnosti. Turizem, razumljen širše kot skupek najrazličnejših sproščujočih se dejavnosti in aktivnosti, ki jih posameznik/skupina počne v prostem času (izjemoma tudi ob drugih prilikah) - v nadaljevanju »turizem « - pogosteje kot kdajkoli poprej spreminja podobo nekdaj $\mathrm{v}$ izključno proizvodnjo naravnane kulturne pokrajine. Izmed motivov, ki pogosteje kot poprej opredeljujejo posameznika ali skupnost in, ki se sosledno odražajo v zahtevah po ustrezni opremljenosti prostora gre izpostaviti splošno naraščanje hedonistične komponente pri posamezniku in v družbi. Iz hedonizma izhajajoče zahteve po »sproščanju « pogojujejo in spreminjajo urbano podobo mest, spreminjajo zahteve po rabi in funkciji podeželja. Proizvodna komponenta družbe, ki je bila nekoč povezana s preživetjem vrste, ni več osrednji in/ali izključni dejavnik v kulturni pokrajini. Nakupovalna središča, wellness centri (karkoli že ti ponujajo oziroma so), naprave in dvorane za modne športne igre, sproščujoče modne aktivnosti v zelenju ali na stičišču voda in kopnega (ter nad in pod njimi) - in, nenazadnje, tudi zavarovana območja, videna iz določenega zornega kota, sodijo v ponudbo hedonistično naravnanemu sodobnemu človeku. Mnogi avtorji se teh sprememb v družbi zavedajo, saj postavljajo omenjeni motiv v ospredje razprav in razumevanja o prostorskih učinkih turizma: "Želja po veselju, zabavi in uživanju življenja je protiutež poklicnemu delu. Čutne užitke, ki jih pobujajo dobra jed, lepa pokraji$n a$, pustolovščine $z$ omejeno nevarnostjo (npr. jadranje $v$ močnem vetru), preračunano tveganje, simulirane naprave za zabavo, igralništvo idr. je možno zadovoljiti prav v prostem času. Ker je uživanje subjektivna zadeva, lahko pobuja "užitek" zelo različne aktivnosti, prireditve, okolje in storitve. (Jeršič, 1999, str. 19). Hedonizem ima v svojem pojmovanju tri izhodišča:

1. filozofsko, ki hedonizem vidi kot etično doktrino, kjer da je naslada/užitek - pojmovano v smislu sreče posameznika ali (redkeje) družbe - dobrina za katero je vredno delovati/ukrepati;

2. psihološko, katere videnje je naravnano na posameznika in po kateri se oseba/posameznik ravna tako, da v življenju išče naslado/užitek in se izogiba bolečim izkustvom; in

3. ljudsko ali splošno, ki izpostavlja dejstvo, da je hedonizem prepričanje posameznika, da je delovanje izključno v smislu iskanja naslade/užitka pravi smisel življenja (Webster, 2000).

\footnotetext{
${ }^{1}$ Razmislek ob priliki 70-letnice dr. Matjaža Jeršiča, red. prof. v pokoju, posredovan na okrogli mizi o turizmu, ki so ga velenjski organizatorji 10. srečanja slovenskih geografov priredili na Velenjskem gradu 21. 10. 2004.
} 
K temu dodajajo nemški avtorji še misel, da je hedonizem »utemeljen filozofski nauk oziroma pogled po katerem je najvišje etično načelo stremljenje po čutni nasladi in zasebni sreči ter izpolnitvi individualno naravnanega fizičnega in psihičnega užitka« (Duden, 2003).

Hedonistični motivi so v preteklosti oblikovali in ustvarili mnoga turistična središča. Ugodja sprehodov ob morju, ki jih je ljubila avstrijska cesarica, je v Opatijo in na njeno »lungo mare« privabil številne obiske s po statusu enakovrednih ali sorodnih plemiških družin ter, sosledno, tudi meščane. Uživanje angleške kraljice Viktorije v kopanju in plavanju v Atlantiku je župane spodbudil, da so v obmorskih mestih gradnjo »boardwalkov« postavili v drugi plan in pričeli graditi kopališča. Mnogo mladih in manj mladih je $\mathrm{v}$ želji slediti zgledu Edgarja Whymperja, ki se je ponašal z osvojitvijo Matterhorna, pričelo obiskovati podobno odročne alpske vasi kot je Zermatt in zaneslo zametke turizma vanje. Z dobrim počutjem so se pohvalili gostje, ki so se odločili »podvreči se« zdravilni metodi Arnolda Riklija, ki je na Bled privabil obiskovalce od blizu in daleč. Potovanjem okrog sveta, ki jih je sprožila angleška turistična agencija Thomas Cook, je sledilo nešteto skupin in posameznikov, med katerimi ne smemo pozabiti naše Alme Karlin in njenih opisov oddaljenih krajev, denimo (danes) turistične Roturoe na Novi Zelandiji, ki med Slovenci še danes pobujajo željo po eksotičnih doživetjih. Ugodja doživljajo tudi deskarji, ki se uspešno zoperstavljajo vetru v prelivu med Korčulo in Pelješcem, ki si je prislužil ime »sredozemski Maui«. Užitke različnih zvrsti si udejanjajo potniki vedno številnejših ladijskih križarjenj, ki bodo imela v prihodnosti svoje izhodišče tudi v Kopru.

Udejanjanje hedonističnih teženj plemstva in meščanstva je $\mathrm{z}$ osrednjim hotelom $\mathrm{z}$ igralnico in plesnimi dvoranami, vilami in parki ter drugo urbano turistično infrastrukturo oblikovalo zametke tradicionalnih turističnih središč v Evropi ob zaključku 19. stoletja, vedno številnejši srednji sloj pa od druge polovice 20 . stoletja dalje na sorodne načine vendar v njim in času lastni maniri (modnost turističnih trendov!) oblikuje »turistične gete« in drugo privlačno in manj privlačno turistično (tudi virtualno) ponudbo/infrastrukturo $\mathrm{v}$ podobnih okoljih po svetu in v bližini doma.

Nekoč opevana naravna in kulturna dediščina kot izrazit, edini vir turistične ponudbe zlagoma izgublja na nekdanjem pomenu, a vedno bolj izstopa kot vrednota, ki bi v primeri povpraševanja po njej oziroma bi, v določeni »preobleki« prednostno avtohtone nravnosti, lahko ostajala/postala temelj turistične dejavnosti. Jeršič pravi: »Naravne prvine same po sebi niso turistično pomembne dokler ne pride do povpraševanja po njih. Naravne prvine so objektivna danost, katere vrednost določajo ljudje s svojimi turističnimi motivi oziroma rekreacijskimi potrebami. Ker motivi ljudi niso enotni, je pomen naravnih prvin za turizem $v$ različnih območjih sveta različen. Ker se turistične navade tudi spreminjajo, se turistična vloga posameznih prvin in pokrajin stalno spreminja« (Jeršič, 1985, str. 60). Napačno pa bi bilo povsem zanemariti oziroma ovreči pomena podedovanih naravnih in kulturnih virov predvsem, če so se le-ti skozi stoletja izkazali kot za turiste izjemno atraktiven ambient. To nedvomno velja za Sredozemlje. V zadnji raziskavi »javnega mnenja turistov«, ki so ga v Sloveniji opravili v letu 2003, poprej pa še leta 1997 in 2000, je bilo ugotovljeno, da je »...okolje (- mišljeno je skupek prednostno naravnih sestavin kulturne pokrajine, ki vključujejo klimo, geomorfološke značilnosti, ipd., - op. pisca) največkrat najbolje ocenjeni element turistične ponudbe, saj je delež zelo pozitivnih (ocena 5) in pozitivnih (ocena 4) ocen 
presegel $87 \%$. Najbolje ocenjujejo slovensko okolje Angleži in Nizozemci, v povprečju nad 90\%. Slovensko gostoljubje pa je zdrknilo v primerjavi z letom 2000 iz 1. na 4. mesto, osebna varnost iz 2. na 3. mesto, in raven gostinskih storitev iz 7. na 8. mesto ... Kakovost okolja se je, nasprotno, pomaknila s 4. na 1. mesto (drugih omembe vrednih premikov v percepciji turistov, ki so obiskali Slovenijo ni bilo, - op. pisca) (Zorko, 2004).

Značilnost znanstvenega pristopa $\mathrm{v}$ okviru geografije turizma ali, poljudneje, turistične geografije je bil njen načeloma pozitiven odnos do razvoja te gospodarske panoge. Pomisleke je veda imela samo v izjemnih primerih, ko je $\mathrm{s} »$ turistično industrijo«, in predvsem urbanimi rešitvami zanjo, naselbinska in splošna podoba krajine utrpela večjo škodo. Pa še takrat je geografija $v$ komparativnih analizah pogosto poskušala dokazovati prednosti razvoja turizma $\mathrm{v}$ razmerju do drugih proizvodnih, transportnih ali sorodnih dejavnosti. Slovenska geografija je bila videna $-\mathrm{z}$ redkimi izjemami (sodobna primera: marina $\mathrm{v}$ Izoli, razvojni koncept Bleda) - kot tesen partner in zagovornik turističnega gospodarstva, saj je zanj ugotavljala primernost za razvoj turizma in se za njegov razvoj zavzemala v skorajda vsakem naravno- in kulturno-geografskem okolju. Tej veji ekonomije je posredovala analize okoljskih dejavnikov in večinsko ugodno vrednotila njih učinke na počutje turistov. $\mathrm{Ob}$ upoštevanju splošnih, globalnih in specifičnih, lokalnih razmer je turističnemu gospodarstvu dajala napotke in smernice za nadaljnji razvoj in širitev. Seveda je turistična geografija analizirala tudi obseg in smer ter učinke turističnega prometa, toda vedno le kot ugotavljanje stanja, videnega skozi prizmo pozitivnih ekonomskih učinkov za mesto, pokrajino, družbo. Turistična geografija je bila promotor (iz)rabe podedovanega, našega, skupnega, vsem dostopnega za potrebe turističnega gospodarstva. Nenazadnje tudi v svrho zaščite pred še bolj v degradacijo okolja naravnanimi drugimi dejavniki gospodarstva in družbe. Prizanesljivo je opozarjala na pretirano širitev turistične dejavnosti, bila je blag nasprotnik vsega prekomernega $\mathrm{v}$ turizmu.

Glede na že kar industrijske razsežnosti delovanja turističnega gospodarstva je geografija primorana vedno pogosteje poročati o »neprijetnih « posledicah, ki jih ta veja gospodarske dejavnosti povzroča globalno ali lokalno. Omeniti velja, denimo, naslednja dejstva:

\section{1. turist je izrazit onesnaževalec ozračja}

- do $60 \%$ iz naslova letalskega prometa, ki se je v desetletju podvojil (1991 - 2001): predvsem zaradi charterskih prevozov in vedno številnejših cenenih letalskih prevoznikov (Ryan Air, Easy Jet, Hapag Lloyd, ...) do oddaljenih turističnih središč/območij (prevoz v okviru »all inclusive« aranžmanov skorajda nima cene - zato lahko že govorimo o svetovni konkurenci turističnih destinacij);

- okrog $75 \%$ vseh nemških turistov se odpravi na počitnice v Sredozemlje z avtom, prevozi v povprečju 1200 kilometrov in pri tem preči številne države in varstvena območja (primer: Turski nacionalni park, Triglavski narodni park) v Alpah in drugod;

- posledično je turist, iz naslova turističnih potovanj, v 5-7 odstotkih odgovoren za porast toplogrednih plinov v zemeljskem ozračju.

\section{2. turist je izrazit porabnik vode}

- povprečen turist porabi, po izračunih WTO - svetovne turistične organizacije, do 880 litrov vode na dan (več v subtropskih območjih): v Španiji je ugotovljeno, da povpre- 
čen turist konzumira dnevno 440 litrov vode na dan po osebi, v Sloveniji ocenjujemo, da za potrebe turizma namenjamo $5 \%$ načrpane vode;

- turistično gospodarstvo je zadolženo, da ob neposredni oskrbi turistov z vodo skrbi, da je vodna oskrba ustrezna v urbanem okolju v hotelskih parkov, predvsem pa na območjih, ki so življenjskega pomena za obstoj njihove dejavnosti - denimo na območjih golf igrišč (namakanje), smučarskih prog (osneževanje), ter nenazadnje v širšem okolju, kjer obstaja nevarnost pogostih požarov.

\section{3. turist je onesnaževalec voda}

- $\quad$ po izračunih WTO posamezni turist dnevno onesnaži okolje z do 180 litri odpadnih voda;

- $\mathrm{k}$ povedanemu pa je treba prišteti še onesnaženje, ki izhaja iz pranja posteljnega perila, spiranja cestišč in posledic nemarnosti v marinah in drugih rekreativnih pristaniščih:

\section{4. turist ustvarja odpadke}

- po izračunih WTO posamezni turist dnevno onesnaži okolje z do 2 kilogramoma osebnih odpadkov, pogosteje v šotoriščih, navtičnem turizmu, ipd.;

- dodatno k temu je potrebno prišteti še tekoče in trdne odpadke hotelskih podjetij v okviru katerih bi naj bilo največ pozornosti deležno kancerogeno, uporabljeno jedilno olje, pa tudi embalaža in podobno.

\section{5. turist onesnažuje prst}

- $\quad$ pri WTO ocenjujejo, da je za $12.000 \mathrm{~km}^{2}$ onesnaženih travnih in gozdnih površin ter podtalnice v Evropi odgovorna turistična industrija, ki na zemljiščih v turistični rabi potresa pesticide, herbicide in sorodne kemične spojine (npr. golf igrišča),

- dodatno onesnaženje prsti povzročajo delavnice v marinah, avtomobilski servisi, ipd.

\section{6. turist ustvarja oziroma širi urbano poselitev in način življenja}

- $\quad$ ocenjujejo, da je v Evropi $550.000 \mathrm{~km}^{2}$ zemljišč prešlo iz agrarnih v urbana zaradi potreb turistične industrije. Med primeri se pogosto omenja pozidava španskih obal in anarhična, razpršena poselitev v Alpah, ki z apartmaji, počitniškimi bivališči, hoteli in zabavišči, pogosto celo brez ustrezno dograjene splošne infrastrukture, ustvarjajo svojsko, turistično, prednostno le sezonsko poseljeno urbano pokrajino. (Cigale, 2004)

\section{7. turist je velik porabnik energije}

- $\quad$ splošna ocena je, da je turist udeležen z do $9 \%$ pri porabi planetarne energije;

Z naštevanjem negativnih, ponekod celo degradirajočih učinkov turizma na lokalno, regionalno in globalno okolje bi lahko še nadaljevali. Stoletje dolgo sledenje zadovoljitve hedonističnega $\mathrm{v}$ posamezniku/skupini, predvsem takrat, ko je to postalo množičen pojav, se je izkazalo za vsaj toliko negativnega za družbo in prostor kot pozitivnega. Turizem, kot smo ga spoznavali doslej, dodobra preoblikuje, vendar tudi uničuje nam znano in priljubljeno prostorsko stvarnost. Turistična geografija spoznava, da je potrebno tesno partnerstvo s turističnim gospodarstvom preoblikovati $\mathrm{v}$ njegovem bistvu: turizmu je potrebno postaviti meje! Razlog za tak razmislek je nenazadnje zaznan že v vsakdanji aplikativni turistični praksi:

- nekatere turistične destinacije, ki jih uprave, oskrbniki oziroma skupnosti smatrajo za posebej ranljive zapirajo vrata turističnim obiskom. Dostop na kopno Antarktike so turis- 
tom v letu 2002 prepovedali, saj »so izletniki z ladij, ob svojem kratkotrajnem obisku obale prekomerno onesnaževali območje in rušili tamkajšnje naravno ravnovesje«. Nekatera območja v Skalnem gorovju ZDA in Kanade so upravitelji nacionalnih parkov izločili iz ponudbe za množični turistični obisk; dovoljujejo obiske le vnaprej najavljenim in ustrezno ekološko osveščenim posameznikom ...

- nekatere turistične destinacije omejujejo oziroma usklajujejo turistične obiske ob viških sezone ali celoletno. V prvi vrsti velja omeniti omejevanje obiska nekaterih mest (npr. Salzburg, Firenze in Benetke, ki dovoljujejo dostop le določenemu številu avtobusov) in reguliranje obiskov izjemne naravne ali kulturne dediščine (denimo v Granadi, Zermattu, Halstattu, Rimu, Dunaju, ...) Najava skupin vnaprej je postalo obligacija za turistične agente, posamezni obiskovalci pa so obdobno soočeni s čakalno vrsto in ob nakupu vstopnice točno določeni uri ob katerih smejo na turistični ogled.

- nekatere turistične destinacije obstoj lastne turistične atrakcije vidijo skozi prizmo trženja, pogost z razlago, da je tak pristop vpeljan iz ekoloških razlogov, saj (dovolj visoka) vstopnina/dajatev sama po sebi omejuje obisk. Užitek je s tem ponovno zagotovljen le eliti. Obiski Himalajskega gorovja v Nepalu je že dolgo vezan na ustrezne »licenčnine«, ki so od 1996 leta dvojne, saj je potrebno določeno vsoto nameniti ne le vladnim institucijam, temveč tudi uporniškim, maostičnim skupinam. Vstopnine v nacionalne parke v Ameriki, Afriki in drugod so ponekod dolgleten, drugod so postale že vsakdanji pojav.

V večini dobro obiskanih turističnih območij pravijo, da ne želijo imeti več turistov - samo bolj zadovoljne, časovno enakomerneje razporejene in bolj »radodarne«! Prav tam in v razvitih družbenih okoljih, z že uveljavljenimi turističnimi središči, se vedno pogosteje zavedajo dejstva, da je množični turistični obisk lahko poguben za krajevno/območno naravo in kulturo. Slogan USTAVIMO TURISTA! (V OKOLJU IN NA OBMOČJU KJER V GLAVNEM ŽE JE!) ni več muha enodnevnica, ampak moto številnih pokrajin. Zavedajo, da sonaravnega turističnega razvoja ni. Vsak obiskovalec spremeni zatečeno prostorsko stvarnost. Pogosto, žal, trajno. Trajnostni turistični razvoj, v smislu zavedanja, in omejevanja ter plašnega poseganja turistične dejavnosti v prostor, lahko edini zagotavlja napredek domačinom in ugodje obiskovalcem, vendar le, če se obe obravnavani stranki tega zavedata. Ne smemo namreč pozabiti, da je turizem vezan na ekonomski dobiček ...

Izkušnja za geografijo in njeno ustrezno učvrščeno znanstveno-raziskovalno disciplino- turistično geografijo je taka, da nakazuje bistvene spremembe $v$ videnju funkcije in učinkov turizma ter turističnega gospodarstva. Dobrohotno obravnavanje širjenja turističnega gospodarstva in izkazano razumevanje za kratkotrajne (turistične) obiske, ki prav zaradi kratkotrajnosti in omejenih učinkov ne bi smeli biti nevarni - tako smo doslej menili, se mora prevesiti v drugo smer. Zavedati se moramo, da je turizem postal industrija in, da jo moramo kot tako tudi obravnavati. Na osnovi gornjih izhodišč je zatorej nujno, da si turistična geografija postavi nove prioritete pri obravnavanju turističnega razvoja v Sloveniji:

1. prioriteta: ohranjanje zdravega okolja - naravne in kulturne dediščine (tudi za ceno manjše ekonomske rasti in omejenega zadovoljevanja hedonističnih motivov); 
2. prioriteta: prestrukturiranje obstoječega turističnega (množičnega, enostranskega) v sodobno turistično gospodarstvo (ekološko ustrezno, dejavnostno raznovrstno in doživljajsko), s pestro, na posameznika naravnano ponudbo;

3. prioriteta: dopolnjevanje ponudbe $\mathrm{v}$ turističnem gospodarstvu s ponudbo drugih sorodnih turističnih ekonomij $\mathrm{v}$ regiji/pokrajini oziroma z drugimi družbenimi (kulturnimi, ljubiteljskimi, ipd.) institucijami in gospodarstvom (primeri: soline v Sečovljah, rudarjenje v Velenju, ipd.), kar naj bogati obe veji gospodarstva;

4. prioriteta: oblikovanje novih produktov turističnega gospodarstva v skladu s sodobnimi načeli trajnostnega razvoja, oziroma s ponudbo manj realnega in več imaginarnega sveta.

V skladu s povedanim se ponujajo kot predlogi nekatere razvojne ideje naravnane na nekatere posamezne turistične segmente $\mathrm{v}$ Sloveniji:

- Sinergija v turizmu: razvoj novega produkta na povezavi starih turističnih produktov primer prekmejnega povezovanja ob slovensko.italijansko-avstrijski tromeji;

- Trajnostni turistični razvoj: oblikovanje novega imidža pokrajine/države na osnovi fizične adaptacije obstoječe turistične infrastrukture $v$ skladu s sodobnimi potrebami in zahtevami v turističnem gospodarstvu - primer Zelene oaze Portoroža na območju Bernardina;

- Kompleksna gospodarska ponudba: ustvarjanje turistične ponudbe v kooperaciji z dobrinami (drugih) nekdanjih ali obstoječih gospodarskih panog oz. drugim ... - primer: doživljajski turizem na kmetijah (»wellness senik«);

- Naravne danosti v novi turistični funkciji: izoblikovanje turističnega produkta, ki bo temeljil na že obstoječem, avtohtono naravnem ali kulturnem, a bo zaživel v drugačni funkciji - primer ponudbe programov »dobrega počutja« ob mineralnih in termalnih vrelcih;

- Virtualni/spominski turizem (»oma/babica so mi povedali«): ustvarjanje nove imaginarne podobe za tradicionalne turistične destinacije - primer oblikovanja zgodovinsko in $\mathrm{z}$ legendami podkrepljenega turizma $\mathrm{v}$ Lipici, ... /tudi s ponudbo kvazi ali resnične virtualnega doživetja/zabave).

\section{Viri in literatura:}

D. Cigale (2004): Posledična navzkrižja in obremenitve slovenskega alspkega sveta zaradi turizma in rekerativne dejavnosti, doktorska disertacija, Oddelek za geografijo, Filozofska fakulteta, Univerze v Ljubljani, Ljubljana, 329 str.;

M. Jeršič (1999): Prostorsko planiranje rekreacije na prostem: priročnik, Ministrstvo za okolje in prostor, Urad RS za prostorsko planiranje, Inštitut za geografijo, Ljubljana, str. 19;

M. Jeršič (1985): Turistična geografija, Univerza Edvarda Kardelja v Ljubljani, Filozofska fakulteta, Oddelek za geografijo, Ljubljana, str. 60

D. Zorko (2004): Tuji turisti o turistični ponudbi Slovenije 2004, Lipov list, sept. 2004, str. $34-35$. 